\title{
PHARMACOLOGICAL AND HEALTH BENEFITS OF MEDICINAL PLANTS
}

\author{
Nisha Vats \\ Department of Life Science, \\ Sharda University, Greater Noida, UP, India \\ Institute of Liver and Biliary Sciences, New Delhi
}

\author{
Pankaj Taneja \\ Department of Life Science, \\ Sharda University, Greater Noida, \\ UP, India
}

\begin{abstract}
Exploration of Medicinal plants for health benefits has wide literature. In the current short review, we have discussed the pharmacological properties with selected Medicinal plants Turmeric, Lufa, Broccoli, Green cress, Moringa, Tulsi and neem. They possess antioxidant, anitinflamatory, antidiabetic, hepato and cardioprotective as well as anticancerous properties. Therapeutic plants have been utilized for quite a long time, and various societies still depend on indigenous therapeutic plants for their essential human services needs. The different parts of these plants including leaves, flowers, stems and roots, etc have different constituents having different medicinal values. It gives brief idea about the medicinal values of the plants.
\end{abstract}

\section{INTRODUCTION}

Medicinal plants are of great demand in current scenario against artificial drugs because of their less side toxic effects and history of its beneficial properties [Kelly et al,2009]. They are known to possess pharmacological health benefits including antioxidant, antinflamatory, antidiabetic, cardioprotective and anti carcinogenic properties etc. Among them includes Turmeric, Lufa Cylindrica, Broccoli, Garden cress, Moringa, Tulsi and neem. Turmeric is an ancient spice herb which possesses hepatoprotective, antinflamatory and anticancerous activity [Agarwal et al,2007]. Lufa possesses antifungal properties [Bashal et al,2012]. Broccoli is antioxidant and cancer preventive agent [Munday et al,2008]. Lepidium or Garden Cress has antidiabetic and hypocholesterolemic activity [Adam et al,1999]. Moringa is antihypertensive and diuretic herb. [Anwar et al,2005]. Tulsi is spiritual herbal drug with antimicrobial, antifungal and anticholestrogenic profile [Gordon et al,2001]. In this review we are discussing the medicinal properties of these selected plants and health benefits.

\section{TURMERIC}

Botanical name: Curcuma longa $\mathrm{L}$.

Turmeric is by and large utilized as a spice and developed all through Indian subcontinent. Turmeric plant has been utilizeas a medicine for curing of different infections. The principle synthetic compound of Turmeric is curcumin [Agarwal et al,2007]. The curcuminoids are polyphenols and are cause for the yellow shade of turmeric. Curcumin can exist in no less than two tautomeric shapes, keto and enol. Curcumin can be utilized for boron quantification (curcumin method]. In Ayurveda, the helpful properties of turmeric portrayed in Kusthagna (Anti-dermatosis), Visaghna (Anti-toxic) Kusthagna (Anti-dermatosis), Dashemani Lekhaniya (emaciating). Rhizome of Haridra (Hindi name of Turmeric) is known to have remedial properties [Mali et al,2011].

Curcumin applies anti-inflammatory activity by inhibition of various distinctive molecules that assume a vital part in inflammatory. Turmeric is successful in lessening postsurgical inflammation. Turmeric anticipates atherosclerosis by lessening the formation of bloods clusters. The antioxidants in turmeric secure against atherosclerosis. A animal studies demonstrate that curcumin brings down cholesterol and triglycerides. In an investigation of atherosclerosis, mice were encouraged a standard American diet and a portion of the mice got this eating regimen in addition to turmeric blended in with their nourishment. Following four months on these weight control plans, the mice that devoured the turmeric with their sustenance had 20 percent less blockage of the supply routes than the mice bolstered the eating routine without the turmeric .In another study, rabbits were encouraged turmeric in addition to an eating regimen (intended to bring about atherosclerosis), had numerous danger variables were made strides [Ponnusamy et al,2010].

Curcumin represses the development of Helicobacter pylori, which is responsible gastric ulcers and has been connected with gastric tumors. It diminishes toxicity heavy metals like cadmium and lead, therefore proves its defensive activity to the brain. Curcumin goes about as an inhibitor for 5lipoxygenase, cyclooxygenase, and glutathione S-transferase. Turmeric is an intense antioxidant.

Curcumin, its fundamental dynamic constituent, is as intense and antioxidant as vitamin $\mathrm{C}$, vitamin $\mathrm{E}$ and Beta-Carotene, therefore turmeric useful in cancer prevention action, liver protection and untimely maturing. Studies likewise demonstrate that turmeric restrains the development of a few 


\section{International Journal of Engineering Applied Sciences and Technology, 2019 Vol. 4, Issue 3, ISSN No. 2455-2143, Pages 195-200 \\ Published Online July 2019 in IJEAST (http://www.ijeast.com)}

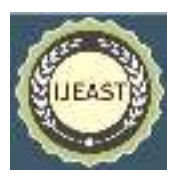

diverse sorts of tumor cells. Curcumin has impact on a different of organic pathways required in mutagenesis, apoptosis, cell cycle control, tumorigenesis and metastasis [Sa et al,2008]. Turmeric goes about as a cholagogue, invigorating bile production, consequently, expanding the bodies' capacity to process fats, enhancing absorption and wiping out toxins from the liver [Salama et al,2013].

Curcuma oil altogether lessens the negative impact of ischemia. So, there is confirmation curcuma oil as a neuroprotective has a high viability, with a great restorative property for the avoidance of ischemic cerebrum damage. At the point when curcumin nourished to ages mice with plaque stores that is like those of Alzheimer's ailment, the measure of plaque affidavit is decreased by cucumin. It decreased oxidative harm and turned around the amyloid pathology in an Alzheimer's ailment transgenic mouse [Dohre et al,2008].

Haridra is utilized as antiparastic as a part of numerous skin affections. Its rhizome powder blended with cow's urine is taken inside in inching and dermatitis. Curcumin got have appeared to have the capacity to shield the skin from destructive UV-prompted impacts. Curcumin has a property to repress nonspecific and particular pole cell-subordinate hypersensitive responses [Yun-Ho et al,2010]. The Curcumin is additionally a powerful medication resistance preventer.

\section{Sponge Gourds}

\section{Botanical name: Luffa Cylindrica L.}

It is a fibrous plant with natural products containing dark seeds. It contains gathering of mixes such asphenolics, lavonoids, oleanolic corrosive, ascorbic corrosive, atocopherol, oleanolic corrosive, carotenoids, chlorophylls, triterpenoids and ribosome-inactivating proteins, which makes it profoundly viable utilized when for therapeutic reason [Bashal et al,2012].

Plant is sour tonic, emetic, diuretic and laxative and valuable in asthma, skin ailments and splenic growth. A study says that administration of ethanol concentrates and water decoction of luffa Oral and Intraperitoneal smothered SO2-and ammonium vaporized impelled hack in mice, and expanded the respiratory tract phenol red discharge in mice. In guinea pigs, intraperitoneal organization of water decoction of it restrained histamine instigated asthma.

It is internally utilized for rheumatism, spinal pain, and hemorrhoids. Youthful flower can be eaten crude like cucumber or cooked like squash, while the youthful leaves, shoots, bloom buds, and in addition the blossoms can be eaten in the wake of being softly steamed. The seeds can be simmered as a nibble, or squeezed to deliver oil. The dried flower is helpful in skin related problems. The flower has anthelmintic, diuretic, depurative, anticancerous, etc properties and is helpful in fever, syphilis, bronchitis, and many infections. In a hypertriglyceridema rat model, oral administration of water decoction diminished serum cholesterol and triglyceride levels, expanded high thickness lipoprotein-cholesterol, and diminished the body weight [Y.Guan et al,2006]. It has anti-inflammatory properties a study proved it, water decoction is administrated intraperitoneal hindered carrageenan impelled plantar edema in rats. Luffacylin inhibited Fusarium oxysporum and Mycosphaerella arachidicola in vitro, proved antifungal activity [Muthumani et al,2010].

The vine is most generally developed for the stringy inside of the fruits. Bit of seed is utilized as a part of looseness of the bowels. Seed oil is utilized as a part of infection and skin related diseases. Oral administration of ethanol concentrate of the stem restrained homologous inactive cutaneous hypersensitivity in rats, heterologous latent cutaneous hypersensitivity in mice, Arthus response in mice, and sheep red platelet instigated deferred sort extreme hypersensitivity in mice, proved anti-allergic properties [L.M.Li et al,2001-Gupta et al,2014]. Fruit has laxative property and utilized for dropsy, bronchitis, nephritis, and lung related diseases. It is additionally protect body from jaundice.

\section{Broccoli}

Botanical name: Brassica oleracea $\mathrm{L}$.

Broccoli is a consumable green plant in the cabbage family. Broccoli has a place with the cruciferous vegetable family, which incorporates kale, cauliflower, Brussels grows, bok choy, cabbage, collard greens, rutabaga and turnips [Mundat et al,2008]. They are rich in vitamin C, dietary fiber furthermore contain glucoraphin, Sulforaphane, isothiocyanates and selenium. Broccoli is additionally rich of indole-3-carbinol. These constituents present in broccoli have anti-cancerous activities. Isothiocyanates, suppress tumor development by creating receptive oxygen species, or by inciting cycle capture prompting apoptosis. Isothiocyanates (ITCs) known class of chemopreventive specialists is found in Broccoli sprouts. Erucin (ER) (dietary ITC), is thought to be a noteworthy disease chemopreventive phytochemical. In any case, ER demonstrated a lower strength in restraining the expansion of prostate adenocarcinoma cells (PC3) . Selenium-advanced broccoli grows, when contrasted with the typical broccoli sprouts are observed to be predominant and incites apoptosis of prostate tumor cells, restrains cell multiplication and reductions prostate-particular antigen emission. Likewise are defensive against artificially affected mammary or colon cancer [Finley et al ,2001-Gullet et al,2010].

Sulforaphane with phytochemicals, for example, indole-3carbinol and brassinin from broccoli have been valuable for tumor chemoprevention [Abdulah et al,2009-Munday et al,2008]. 


\section{International Journal of Engineering Applied Sciences and Technology, 2019 Vol. 4, Issue 3, ISSN No. 2455-2143, Pages 195-200 \\ Published Online July 2019 in IJEAST (http://www.ijeast.com)}

Broccoli is generally utilized as a part of the treatment of cancer furthermore treats other neural issue. The remedial capability of broccoli has been clarified under its part in tumor, diabetes and different infections. Other different phytochemicals, for example, glucosinolates, glucoraphin and sulforaphane of broccolli impelled antioxidant property. Sulforaphane in broccoli can possibly cure neural related diseases, for example, Alzheimer's and Parkinson's diseases. It is likewise utilized to achieve cure in asthma and diabetic patients. Flavonoids have the impact of decreasing the danger of diabetes. The broccoli sprouts are known to improve insulin resistance in sort 2 diabetic patients and its difficulties. Sulforaphane additionally avoid nephropathy, diabetesimpelled fibrosis and vascular complications [Vale et al,2015]. Sulforaphane prevents neurodegeneration and has effect on Parkinson's disease and Alzheimer's disease.

Sulforaphane contained in Broccoli sprout extract (BSE) used to suppress the nasal inflammatory response. Glucosinolates in Brassica plants has antioxidant properties. During the sprouting broccoli, being one of the varieties of Brassica sprouts is grown to evaluate the glucosinolate profile and myrosinase activity. Sulforaphane is used as an antioxidant dietary supplement [Nettleton et al,2006].

\section{Garden cress}

Botanical name: Lepidium sativum $L$

It is a quickly developing yearly herb that is local to Egypt and West Asia, in spite of the fact that it is presently developed in the whole world. Its seeds are rich source of proteins Leucine, glutamic, methionin, linolenic acid, erucic acid, dietary fiber, omega-3 unsaturated fats, iron, other vital supplements and phytochemicals [Adam et al,1999]. Garden cress is generally for the treatment of asthma, bronchitis and hack. It has properties - phytochemical, antimicrobial, toxicology and therapeutic.

Gc seed were tried both in vitro and in vivo, it was watched most elevated diminishment in-vitro rate of starch hydrolysis. Examines demonstrated that both control and diabetic groups supper with Gc seeds the glycemic reaction brought when contrasted down with the feast without Gc seeds. It proved its anti-diabetic property. In a study the antidiarrheal property of methanolic concentrate of Gc Seed is considered. In three experimentally induced diarrhea models the antidiarrheal action was seen, they are Castor oil prompted diarrhea; Prostaglandin E2 (PG-E2) prompted enteropooling in rats; Charcoal feast test in mice. Conclusion for this study was that antidiarrheal movement is controlled by methanolic concentrate of Gc seeds [Patole et al,1998].

Many studies were done to show that Gc has pain relieving activity. Intraperitonealy treatment is given to animal with aggregate alkaloids from Gc seeds. Conclusion was that Gc seed show soothing and pain relieving action [Atasan et al,1989]. A study reported the bronchodilator properties of Gc seed unrefined extract which demonstrates its therapeutic use in the hyperactive respiratory issue, for example, asthma and cough [Paranjae et al,2006]. The capability of watery concentrate of Gc seeds to actuate apoptosis in human breast tumor cells. The capability of Gc seed concentrate to prompt apoptosis in the cell line MCF-7, contrasted with HFS, was resolved. Apoptosis was prompted in cells, more in MCF-7, when they were treated with extract [Kassie et al,2002]. Galactagogue properties of Gc seeds were considered in grown-up female virgin Norway rats.

\section{Moringa/ drumstick tree}

Botanical name: Moringa oleifera $L$.

Moringa oleifera Lam (Moringaceae) is an exceptionally esteemed plant, conveyed in numerous nations of the tropics and subtropics [Anwar et al,2005]. It has a noteworthy scope of therapeutic uses with high nutritious quality. Diverse parts of this plant contain a profile of imperative minerals, and are a decent wellspring of protein, vitamins, $\beta$ - carotene, amino acids and different phenolics. The Moringa plant gives a rich and uncommon blend of quercetin, zeatin, $\beta$ - sitosterol, and kaempferol.

Different parts of this plant, for example, the leaves, seeds, roots, bark, blooms and flowers etc, go about as heart and circulatory stimulants, have many medicinal properties.

The new leaf juice was found to hinder the development of a few microorganisms that Moringa leaves have antitumor properties. Fluid leaf concentrates of Moringa oleifera control thyroid hormone and can be utilized to treat hyperthyroidism [Caceres et al,1991]. Moringa part that is flower has been found to bring down the serum cholesterol, phospholipids, triglycerides, low thickness lipoprotein (LDL), low thickness lipoprotein (VLDL) cholesterol to phospholipid proportion, atherogenic file lipid and decreased the lipid profile of liver, heart and aorta in hypercholesteremic rabbits and expanded the discharge of fecal cholesterol [Ghasi et al,2000]. Moringa roots have antibacterial action [Rao et al ,2001]. Pterygospermin is dynamic anti-toxin standard contained which has antibacterial and fungicidal impacts [Ruckmani et al,1998]. A comparable compound is observed to be in charge of the antibacterial and fungicidal impacts of its blooms. That the bark extricate have antifungal action while the juice from the stem bark indicated antibacterial, and are being utilized for the treatment of various illnesses in the indigenous system of medicine, especially in South Asia [Bhatnagar et al,1961]. It even purifies the water. Moringa seeds have particular protein divisions for skin and hair care. Two new dynamic segments for the restorative business have been extricated from oil cake. Purisoft ${ }^{\circledR}$ comprises of peptides of the Moringa seed. It shields the human skin from ecological impacts and battles untimely skin maturing. 


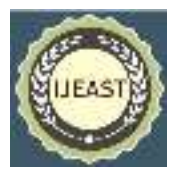

6. Tulsi

Botanical name: Ocimum sanctum L.

Ocimum tenuiflorum additionally called Ocimum sanctum, blessed basil, or tulasi. It is an erect, numerous extended subshrub, with bristly stems and has phyllotaxic green or purple leaves that are emphatically scented [Gordon et al,2001]. The leaves of Ocimum sanctum contain volatile oil including around eugenol and methyl eugenol. The leaves are demulcent, diaphoretic and expectorant in bronchitis, cold and cough. It is a deodorizer and likewise has been utilized as purgative, stimulant and mitigating, cardio tonic and blood purifier in hepatic issue. It can be utilized for digestion problems, lessened appetite and a wide range of discomfort. The oil may used for ulcers, aggravation and skin issue [Singh et al ,1991; Ganasounri et al ,1998 and Aruna et al,1996 ]. The medicinal properties of fundamental oils separated from the crisp leaves of Ocimum sanctum has been asserted because of the of eugenol which is the real constituent of crucial oils a phenolics mixes (1-hydroxy - 2-methoxy-4-allyl benzene). It has been observed the critical action of eugenol, separated from Tulsi leaves on digestive system, immune system, CNS (central nervous system)and so on. In animal model eugenol indicates antidiabetic, triglyceride cholesterol diminishing activity and other symptomatic clinical catalysts in blood serum LDH, GPT, GOT and basic phosphatase portraying the helpful possibilities of Ocimum sanctum as antidiabetic, hypolipidimic, hepatoprotective specialist. Eugenol likewise indicates vasodilator impact on rabbit blood vessel tissues . Ocimum (whole plant) is utilized as a part of ulcers, hatchlings in wounds, pneumonia, Bacillus anthracis, digestion problems, tympanitis (irritation of inward ear), stomach problems, liver problems, ,cannabis harming, murkiness of cornea, tachycardia, sore eyes, sprains. The leaves are utilized as in eye problems, bleeding and udder contaminations [Singh et al,1996]. The ethanolic concentrate of Tulsi leaves lead to stamped bringing down of glucose in typical glucose nourished hyperglycaemic and streptozocin actuated diabetic rats [Skaltsa et al,1987].

\section{Neem}

\section{Botanical name: Azadirachta indica $\mathrm{L}$.}

Neem is a standout amongst the most encouraging therapeutic plant, having wide range bacterial and insecticidal properties. All aspects of neem tree have been known to have extensive variety of pharmacological properties-antibacterial, antifungal, antiulcer, antifeedant, repellent, pesticide, inhibitor and sterilant. This local tree of India which is eco-friendly tree is most investigated tree. Water dissolvable extract of A. indica leaves was found to have huge hypoglycemic, hypolipidemic, hepatoprotective, against richness and hypotensive properties .Parasitic diseases of yield plants have dependably been one of the significant imperatives in fruitful crop generation which causes extreme yield misfortune consistently. Tactless utilization of manufactured fungicides for controlling plant infections have offered ascend to negative impacts on human and animal well being and agro-biological community. Therefore, the scientists are certain about creating other options to chemical fungicides. The neem contains no less than 35 naturally dynamic standards of which nimbin and azadirachtin are the most dynamic insecticidal fixings and are available generally in the seeds, leaves and different parts of the neem tree [kumari et al ,2013]. Some of the chemical constituents extracted from parts of neem plants are Sodium Nimbidate, Nimbidin, Gallic Acid, Catechin, Cyclic Trisulphide and cyclic tetrasulphide possess pharmacological activities. The internal therapeutic uses of neem incorporate malaria, tuberculosis, stiffness, joint inflammation, jaundice and intestinal worms and also skin problems.

The oil is not ordinarily taken inside - however as a decoction produced from leaves. The neem leaves extract has antidiabetic properties. Neem additionally upgrades the immune system - making it a conceivable substance of utilization for AIDS and tumor patients. It additionally diminishes glucose levels -making it a conceivable compelling compound for diabetic patients. The extracts are likewise helpful for heart problems, hepatitis, intestinal sickness, psoriasis, and ulcers. Neem is utilized remotely for ringworm, skin inflammation, psoriasis, lice, contagious disease and also for difficult joints furthermore, muscles. The utilization of Neem oil incorporates the fighting of skin inflammation and pimples also as enhancing skin elasticity

Niombidin is useful against different skin related diseases effective such as dermitis, eczema and scabies, etc . It has antiprotozoal properties. Paramaecium candatum was killed Nimbidin and Sodium Nimbidinate (more potent) [Mohammed et al].

\section{CONCLUSION}

These plants have extraordinary medicinal properties. The phytochemicals extracted from these discussed plants parts including flowers, fruits, leaves and stems have been demonstrated to minimize the risk of several major diseases including cancers, neurodegenerative disorders, and diabetes.

\section{ACKNOWLEDGEMENT}

I thank Dr Pankaj Taneja, Associate professor, Sharda university for encouraging me, helping me and for comments that greatly improved the manuscript

\section{REFERENCES}

1. Kelly K., (2009). History of medicine. New York: Facts on file; pp. 29-50.

2. Agrawal S., (2007). Herbal Drug technology, Universities press (India) Private Limited, Hyderabad, India; 1. 


\section{International Journal of Engineering Applied Sciences and Technology, 2019 Vol. 4, Issue 3, ISSN No. 2455-2143, Pages 195-200 \\ Published Online July 2019 in IJEAST (http://www.ijeast.com)}

3. Bashal SK and Sudarsanam G,(2012). Traditional Use of Plants against Snakebite in Sugali tribes of Yerramalais of Kurnool district, Andhra Pradesh, India. Asian Pacific Journal of Tropical Biomedicine ; 1691(12):60276-7.

4. Munday R, Mhawech-Fauceglia P, Munday CM, Paonessa JD, Tang L, et al, (2008). Inhibition of Urinary bladder carcinogenesis by broccoli sprouts. Cancer; Res 68: 1593-1600.

5. Adam SE,(1999). Effects of various levels of dietary Lepidium sativum Linn. in rats. Am. J. Chin. Med. 27,397-405.

6. Anwar F, Ashraf M, Bhanger MI,(2005). Interprovenance variation in the composition of Moringa oleifera oilseeds from Pakistan. J Am Oil Chem Soc; 82: 45-51.

7. Gordon MC, David JN,(2001) Naturan product drug discovery in the next millennium. Pharm Boil ;39:817.

8. Mali R, Dhake A,(2011).A review on herbal antiasthmatics. Orient Pharm Exp Med;11: 77- 90.

9. Ponnusamy S, Ravindran R, Zinjarde S, Bhargava S, Ameeta R (2011) Evaluation of Traditional Indian Antidiabetic Medicinal Plants for Human Pancreatic Amylase Inhibitory Effect In Vitro .EvidenceBased.Complementary and Alternative Medicine $.2010 ; 10$.

10. Sa G, Das T (2008) Anti cancer effects of curcumin: cycle of life and death. Cell Div 3: 14.

11. Salama SM, Alrashdi AS, Ismail S, AlkiyumiSS, Abdulla MA, et al.(2013). Hepatoprotective effect of ethanolic extract of Curcuma longa onthioacetamide induced liver cirrhosis in rats.BMC Complementary and Alternative Medicine 13: 56.

12. Dohare P, Garg P, Sharma U, Jagannathan NR, Ray $M$ (2008). Neuroprotective efficacy and therapeutic window of curcuma oil: in rat embolic stroke model. BMC Complementary and Alternative Medicine; 8: 55.

13. Yun-Ho C, Guang-Hai Y, Ok Hee C, Chang Ho S (2010). Inhibitory effects of curcumin on passive cutaneous anaphylactoid response and compound 48/80-induced mast cell activation. Anat Cell Biol 43: $36-43$.

14. Y.Guan, J.Li, WJ.Zhu, L.Sun, Y.M.Fu(2006). Chinese J Pathophy; 22(1): 68-71
15. P Muthumani, R Meera, Subin Mary, Jeenamathew, P Devi, B Kameswari, B Eswara priya (2010). Phytochemical Screening and Anti inflammatory, Bronchodilator and Antimicrobial activities of the Seeds of Luffa cylindrica. Research Journal of Pharmaceutical, Biological and Chemical Sciences. ;1(4):11-22.

16. L.M.Li, M.Nie, Y.L.Zhou, S.B.Qi, Y.M.Hu. West China J of Pharm Sci 2001; 16(5): 334- 336

17. J.P.Kou, S.F.Zhuang, X.J.Tang, C.N.Tong, Y.Q.Yan(2001). J China Pharm Univ ; 32(4): 293296.

18. Gupta Parul , Bonglee Kim, Sung-Hoon K, Srivastava SK (2014) Molecular targets of isothiocyanates in cancer: recent advances. Molecular Nutrition and Food Research 58: 1685-1707.

19. Finley JW, Ip C, Lisk DJ, Davis CD, Hintze KJ, et al. (2001) Cancer-protective properties of high-selenium broccoli. J Agric Food Chem 49: 2679-2683.

20. Gullett NP, Amin ARR, Bayraktar S, Pezzuto JM, Shin DM, et al. (2010). Cancer prevention with natural compounds. Semin Oncol 37: 258-281.

21. Abdulah R, Faried A, Kobayashi K, Yamazaki C, Suradji EW, et al. (2009) Selenium enrichment of broccoli sprout extract increases chemosensitivity and apoptosis of LNCaP prostate cancer cells. BMC Cancer 9: 414.

22. Munday R, Mhawech-Fauceglia P, Munday CM, Paonessa JD, Tang L, et al. (2008) Inhibition of Urinary bladder carcinogenesis by broccoli sprouts. Cancer Res 68: 1593-1600.

23. Vale AP, Santosa J, Britob NV, Fernandesb D, Rosac E, et al. (2015) Evaluating the impact of sprouting conditions on glucosinolates content of Brassica oleracea sprouts. Phytochemistry. (In press).

24. Bahadoran Z, Tohidi M, Nazeri P, Mehran M, Azizi F, et al. (2012) Effect of broccoli sprouts on insulin resistance in type 2 diabetic patients: a randomized double-blind clinical trial. Int J Food Sci Nutr 63: 767-771.

25. Nettleton JA, Harnack LJ, Scrafford CG, Mink PJ, Barraj LM, et al. (2006) Dietary flavonoids and flavonoid-rich foods are not associated with risk of type 2 diabetes in postmenopausal women. J Nutr 136: 3039-3045. 


\section{International Journal of Engineering Applied Sciences and Technology, 2019 \\ Vol. 4, Issue 3, ISSN No. 2455-2143, Pages 195-200 \\ Published Online July 2019 in IJEAST (http://www.ijeast.com)}

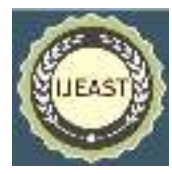

26. Patole AP. (1998) Effect of mucilaginous seeds on in vitro rate of starch hydrolysis and blood glucose levels of NIDDM subjects with special reference to garden cress seeds. J. Med. Aro. Plant Sci. 20, 1005 1008.

27. Atasan SK. (1989) Studies on some herbal drugs used in fracture healing. Int. J. Crudee Drug Res. 27, 235239.

28. Paranjape AN, Mehta AA. (2006) A study on clinical efficacy of Lepidium sativum seeds in treatment of bronchial asthma. Iranian J. Pharmacol. Ther. 5, 55-59.

29. Kassie F, Rabot S, Uhl M, Huber W, Qin HM, Helma C, Schulte-Hermann R, Knasmuller S. (2002). Chemoprotective effects of garden cress (Lepidium sativum) and its constituents towards 2-amino-3methyl-imidazo[4,5-f]quinoline (IQ)-induced genotoxic effects and colonic preneoplastic lesions. Carcinogenesis23, 1155-1161.

30. Caceres A, Lopez S. (1991). Pharmacologic properties of Moringa oleifera: 3: Effect of seed extracts in the treatment of experimental Pyodermia. Fitoterapia 62: 449-450.

31. Ghasi S, Nwobodo E, Ofili JO (2000). Hypocholesterolemic effects of crude extract of leaf of Moringa oleifera Lam in high-fat diet fed Wistar rats. J Ethnopharmacol 69: 21-25.

32. Mehta LK, Balaraman R, Amin AH, Bafna PA, Gulati OD. (2003). Effect of fruits of Moringa oleifera on the lipid profile of normal and hypercholesterolaemic rabbits. J Ethnopharmacol 86: 191-195.

33. Rao VA, Devi PU, Kamath R. (2001). In vivo radioprotective effect of Moringa oleifera leaves. Indian J Exp Biol 39: 858-863.

34. Ruckmani K, Kavimani S, Anandan R, Jaykar B. (1998). Effect of Moringa oleifera Lam on paracetamol-induced hepatoxicity.Indian J Pharm Sci 60: $33-35$.

35. Bhatnagar SS, Santapau H, Desai JDH, Yellore S, Rao TNS. (1961). Biological activity of Indian medicinal plants. Part Antibacterial, antitubercular and antifungal action. Indian J Med Res 49: 799-805.
36. Singh S, Aggarwal S.S.(1991). Antiasthmatic \& antiinflammatory activity of ocimum sanctum. International Journal of pharmacognosy; 29(4). 306.

37. Ganasoundri A. Devi P.U, Rao B.S (1998).Enhancement of bone marrow radio protection \& reduction of W.R-2721 toxicity of Ocimum sanctum. Mutation research ; 397(2).303

38. Aruna K, Sivarama Krishnan

V.M.(1996). Anticarcinogenic effects of the essential oils from cumin, poppy \& basil. Phytotherapy research; (10).577.

39. Singh S. Majmudar D.K, Yadav M.R.(1996). Chemical \& pharmacological study on fixed oil ofocimum sanctum. Indian journal of experimental biology;34 (12).1212p.

40. Skaltsa M, Couladi M , Philianos S, Singh M(1987). Phytochemical studies of the leaves of Ocimum sanctum : fitotdepia ;58(4) 286.

41. Kumari Anjali, Kumar Ritesh, Sudarshan Maurya, Choudhary Jaipal Singh , Kumar S (2013).Antifungal efficacy of aqueous extracts of neem cake, karanj cake and vermicompost against some phytopathogenic fungi, The Bio scan, 8(2): 671-674.

42. Pharmacognosy \& Phytochemistry, Mohammed Ali ,Vol-1, 680 -681. 